\title{
White Blood Cell Count and Sleep Difficulty Examined by the Athens Insomnia Scale in Shift Workers
}

\author{
Naoko Nishitani ${ }^{1}$ and Hisataka Sakakibara*,2 \\ ${ }^{1}$ Toray Industries, Inc., Aichi Plant, 1-1-1, Horikoshi, Nishi-ku, Nagoya 451-8666, Japan \\ ${ }^{2}$ Nagoya University School of Health Sciences, 1-1-20, Daiko-minami, Higashi-ku, Nagoya 461-8673, Japan
}

\begin{abstract}
The aim of this study was to examine the relation between sleep difficulty and white blood cell (WBC) count in shift workers. This was a cross-sectional study in male Japanese workers at a synthetic fiber plant. The subjects were 212 male workers who underwent an annual workplace health checkup in April 2007. For the WBC count the blood test value from the health checkup was used. With regard to insomnia, subjects were asked the first 5 of the 8 questions on the Athens Insomnia Scale (AIS). An increased WBC count was associated with total AIS score $(\mathrm{p}<0.05)$ and work pattern (shift work) $(\mathrm{p}<0.05)$ in addition to smoking $(\mathrm{p}<0.001)$, fasting blood sugar $(\mathrm{p}<0.01)$, and BMI $(\mathrm{p}<0.05)$. In shift workers, the WBC count was related with total AIS score $(\mathrm{p}<0.05)$ and those with higher total AIS score tended to have an increased WBC count $(\mathrm{p}<0.01)$. In daytime workers, the count was not associated with AIS score. The present results have shown that shift workers with sleeping problems are more likely to have higher WBC counts, which might suggest low-grade inflammatory changes in those workers. Quality sleep may be necessary for shift workers in particular.
\end{abstract}

Keywords: Sleep difficulty, white blood cell count, shift work, the Athens Insomnia Scale, inflammation.

\section{INTRODUCTION}

Sleep disorders are shown to cause elevations in cytokine interleukin-6 (IL-6), a cytokine shown to be associated with inflammatory responses and immunity, which is related to sleep quality and depth, rather than to duration of sleep [1, 2]. A temporary sleep deprivation experimentally produced an increase in IL-6 during the following day, leading to drowsiness and fatigue [1]. In addition to IL-6, immune and inflammatory response indicators such as natural killer cells (NK cells) and lymphocytes are also reported to be elevated when sleep is disturbed [3, 4]. Sleep loss was found to be associated with leukocytes and increased NK cell activity [5]. Similarly, C-reactive protein (CRP) is shown to be elevated by sleep disturbance [6].

Sleep disturbance is common in shift work of all kinds [7]. Reduced sleep durations has been associated with increased risks of coronary artery disease [8] and diabetes mellitus $[9,10]$. Shift work which includes night shifts in particular is more likely to lead to atherosclerotic disease such as coronary artery disease [11-13]. Glucose metabolism is also easily affected, and lack of sleep tends to cause abnormal blood sugar levels $[14,15]$. Recent studies have shown that shift workers are more liable to have hyperlipidemia accompanied by visceral obesity, which is associated with metabolic syndrome, and they have higher white blood cell (WBC) counts than daytime workers [16]. Thus, shift workers are more likely to have the increased risk of atherosclerotic diseases.

*Address correspondence to this author at the Nagoya University School of Health Sciences, 1-1-20, Daiko-minami, Higashi-ku, Nagoya 461-8673, Japan; Tel/Fax: +81-(0)52-719-1923; E-mail: sbara@met.nagoya-u.ac.jp
Sleep disturbances induced by shift work might possibly promote inflammatory responses and contribute to atherosclerotic diseases in shift workers. However, there have been few field studies on chronic effects of sleep disturbances on blood inflammatory responses. Hence, we investigated chronic effects of sleep difficulty on blood inflammatory responses in shift workers. Quality of sleep was examined by the Athens Insomnia Scale (AIS) [17], an insomnia scale used internationally. The AIS has been used in some recent papers with various populations, e.g. depression patients and adolescents $[18,19]$. As an indicator of inflammatory response, the WBC was used, because it is generally examined at an annual health checkup in Japan.

\section{METHODS}

\section{Subjects}

The subjects were 212 male workers at a synthetic fiber plant who underwent an annual workplace health checkup in April 2007. All workers at this plant underwent this health checkup. This plant has both daytime and shift workers. The working hours for daytime workers are 8:30-17:00. The shift workers are divided into four groups, who work on three separate shifts: morning shift (7:00-14:00), afternoon shift (14:00-22:00), and night shift (22:00-7:00) (Table 1). Both daytime workers and shift workers included a mixture of office and plant workers. The daytime workers underwent the health checkup during the morning of a working day, and the shift workers received the health checkup during the morning on a day in which they work the afternoon shift. On the day before the health checkup, the shift workers worked the afternoon shift or had a holiday.

\section{Procedures}

A self-administered questionnaire survey on living habits and sleep status was conducted among the 212 subjects as a 
Table 1. Shift Schedules

\begin{tabular}{|c|c|c|c|c|c|c|c|}
\hline Schedule & Sunday & Monday & Tuesday & Wednesday & Thursday & Friday & Saturday \\
\hline \hline Group 1 & A & A & A & A & - & M & M \\
\hline Group 2 & N & N & - & - & A & A \\
\hline Group 3 & M & - & N & N & N & N & - \\
\hline Group 4 & - & M & M & M & M & - & N \\
\hline
\end{tabular}

M: morning shift (7:00-14:00); A: afternoon shift (14:00-22:00); N: night shift (22:00-7:00).

- : not at work (holiday)

part of the annual health checkup. The questionnaire was distributed about one week before the health checkup, and at the time of the health checkup was examined by the occupational health nurse for missing information before being collected. The questionnaires were collected from workers who consented to participate in the study and signed an informed consent form. The questionnaires were collected from 210 workers, for a $99.1 \%$ collection rate. Eighteen of these 210 workers were excluded, including 4 who were undergoing treatment for psychiatric disorder, 3 for diabetes, 3 for hyperlipidemia, 3 for gout, 2 who were under observation following cancer treatment, 1 who was receiving dialysis, 1 who was receiving hormone therapy, and 1 who had a cold on the day of the health checkup. A further 8 were excluded because fasting blood tests could not be done on the day of the health checkup. The analysis was therefore conducted with 184 workers (age 19-62 years, mean age 38.2 (SD 12.9) years) who underwent the health checkup and provided a complete questionnaire.

This study was approved by the ethics committee of Nagoya University School of Medicine, Nagoya, Japan.

\section{Measures}

The questionnaire included items on basic subject attributes and living habits, including age, work pattern, whether living with family, type of work, overtime work hours, mean sleeping hours, regular exercise or not, smoking status, and alcohol consumption. For mean sleeping hours, subjects were asked to give mean hours on working days. Daytime workers were asked mean sleeping hours on weekdays, and shift workers were asked mean sleeping hours when working on each of the shifts; morning shift (7:00-14:00), afternoon shift (14:00-22:00), and night shift (22:00-7:00) (Table 1). With regard to insomnia, subjects were asked the first 5 of the 8 questions on AIS, an international measure of insomnia. Although the AIS has a total of 8 questions, it is possible to use just the first five. These 5 questions are assessing difficulty with sleep induction (sleep induction), awakenings during the night, early morning awakening (final awakening), total sleep time (total sleep duration) and overall quality of sleep (sleep quality). The last three items in the 8 questions on AIS refer to daytime symptoms which often result from sleep disorders rather than insomnia, such as narcolepsy and obstructive sleep apnea in insomniac patients [17]. According to the 5 questions, subjects were asked if they had experienced sleep difficulty more than three times a week in the last one month. The responses were selected from four options: not a problem ( 0 point), slight problem (1 point), considerable problem ( 2 points), and could not sleep (3 points). The 8 questions of the AIS can be evaluated with total score, with total score of less than 4 points taken to in- dicate there is no problem, a score of 4 or 5 points to indicate that consultation with a physician may be necessary (some suspicion of insomnia), and a score of 6 or more points to indicate that a physician consultation is necessary (suspected insomnia) [20].

For the WBC count the blood test value from the health checkup was used. At the health checkup, $2 \mathrm{ml}$ of venous blood was collected in a heparinized tube. The WBC count was measured on the day by the Handa Medical Association using a Sysmex SE-9000, Handa, Japan. Body mass index (BMI) was calculated from height and weight at the time of the health checkup.

\section{Analysis}

In the analysis, the relationship between sleep difficulty and WBC count was investigated as follows. Regression analyses considering age were performed to investigate the association of WBC count with each item of basic attributes, lifestyle and blood test value. Multiple regression analysis was then conducted by stepwise method for items in which a significant difference was seen. In addition, multiple regression analyses were performed using stepwise method by work pattern as well. These statistical analyses were completed using SPSS 12.0.

\section{RESULTS}

\section{Basic Attributes, Living Habits, Blood Pressure and Blood Test Results, and WBC Count}

In age-adjusted regression analyses (Table 2), WBC counts were associated with smoking habits $(\mathrm{p}<0.001)$, fasting blood sugar $(\mathrm{p}<0.01)$, work pattern $(\mathrm{p}<0.05)$, BMI $(\mathrm{p}<0.05)$, and total AIS score $(\mathrm{p}<0.05)$. Then, as shown in Table 3, multiple regression analysis considering these items showed significant relations of WBC count with smoking habits $(p<0.001)$, fasting blood sugar $(p<0.01)$, BMI $(\mathrm{p}<0.05)$, total AIS score $(\mathrm{p}<0.05)$, and work pattern $(\mathrm{p}<0.05)$.

\section{Relation Between WBC Count, Sleep and Work Pattern}

In multiple regression analyses by work pattern (Table 4), the WBC count was associated with smoking habits $(\mathrm{p}<0.01)$ and fasting blood sugar $(\mathrm{p}<0.01)$ among daytime workers. In shift workers, the count was related with total AIS score $(\mathrm{p}<0.05)$ as well as BMI $(\mathrm{p}<0.001)$ and smoking habits $(\mathrm{p}<0.01)$.

\section{DISCUSSION}

The present multiple regression analysis indicated that WBC count was associated with total AIS score and work pattern in addition to smoking habits, fasting blood sugar and 
Table 2. Standardized Correlation Coefficient $(\beta)$ with White Blood Cell Count in Age-Adjusted Regression Analysis

\begin{tabular}{|c|c|c|c|}
\hline Item & $\boldsymbol{\beta}$ & $\boldsymbol{t}$ & p value \\
\hline \hline Smoke & 0.322 & 4.527 & 0.001 \\
\hline Fasting blood sugar & 0.234 & 3.051 & 0.003 \\
\hline Work pattern & 0.190 & 2.513 & 0.020 \\
\hline BMI & 0.172 & 2.357 & 0.036 \\
\hline Total AIS score & 0.155 & 2.114 & 0.100 \\
\hline HDL-cholesterol & -0.123 & -1.654 & 0.151 \\
\hline Exercise & -0.107 & -1.443 & 0.305 \\
\hline Overtime work & -0.079 & -1.030 & 0.437 \\
\hline Systolic BP & 0.063 & 0.779 & 0.438 \\
\hline Alcohol & 0.061 & 0.777 & 0.696 \\
\hline Total cholesterol & 0.031 & 0.391 & 0.357 \\
\hline Diastolic BP & 0.028 & -0.270 & 0.105 \\
\hline Sleeping hours & -0.020 & 0.008 & 0.787 \\
\hline Triglycerides & & & 0.916 \\
\hline
\end{tabular}

Table 3. Standardized Correlation Coefficient ( $\beta$ ) with White Blood Cell Count in Multiple Regression Analysis Using Stepwise Method

\begin{tabular}{|c|c|c|c|}
\hline Item & $\boldsymbol{\beta}$ & $\boldsymbol{t}$ & $\mathbf{p}$ value \\
\hline \hline Smoke & 0.325 & 4.840 & $<0.001$ \\
\hline Fasting blood sugar & 0.192 & 2.790 & 0.006 \\
\hline BMI & 0.163 & 2.382 & 0.018 \\
\hline Total AIS score & 0.157 & 2.338 & 0.020 \\
\hline Work pattern & 0.135 & 2.002 & 0.047 \\
\hline
\end{tabular}

$\mathrm{R}^{2}=0.219$, adjusted $\mathrm{R}^{2}=0.197$.

Table 4. Standardized Correlation Coefficient ( $\beta$ ) with White Blood Cell Count in Multiple Regression Analysis Using Stepwise Method by Work Pattern

\begin{tabular}{|c|c|c|c|c|c|c|c|}
\hline \multicolumn{4}{|c|}{ Daytime (n=106) } & \multicolumn{3}{c|}{ Shift (n=78) } \\
\hline Item & $\boldsymbol{\beta}$ & $\boldsymbol{t}$ & $\mathbf{p}$ value & Item & $\boldsymbol{\beta}$ & $\boldsymbol{t}$ & $\mathbf{p}$ value \\
\hline \hline Smoke & 0.298 & 3.337 & 0.001 & BMI & 0.440 & 4.520 & $<0.001$ \\
\hline Fasting blood sugar & 0.291 & 3.268 & 0.001 & Smoke & 0.347 & 3.561 & 0.001 \\
\hline & & & & Total AIS score & 0.252 & 2.628 & 0.010 \\
\hline
\end{tabular}

\section{Daytime}

$\mathrm{R}^{2}=0.185$, adjusted $\mathrm{R}^{2}=0.169$

Shift

$\mathrm{R}^{2}=0.322$, adjusted $\mathrm{R}^{2}=0.295$

BMI. Higher WBC counts were more frequently found in shift workers with sleeping problems than those without the problems. In contrast the WBC count was not associated with sleeping problems in daytime workers. The present results thus demonstrated that shift workers with sleep disturbances were more likely to have elevated WBC counts.
An earlier study showed that, in sleep disturbances such as temporary deprivation of sleep, the cytokine IL-6 is elevated during the following day, leading to drowsiness and fatigue [1]. Increased IL-6 in sleep disturbances has been shown to be related to quality of sleep such as the depth of sleep rather than the duration of sleep $[1,2]$. IL-6, NK cell, and lymphocytes are known to increase following lack of 
sleep [3, 4, 21-23]. Activation of NK cells is also reported to be associated with increased WBC count [5]. Elevated levels of CRP, a typical indicator of inflammation, are also reported to occur with general lack of sleep or poor sleep [6], though a recent study has reported decreased CRP [24]. Earlier findings have thus indicated that the quality and quantity of sleep causes changes in inflammatory reactions and immune function. Recently, moderate-to-severe sleep disturbances in men were associated with slightly increased CRP levels at the epidemiological level [25]. The present study examined the relationship between white blood cells and sleep difficulties, as chronic effects such as those from shift work. The results indicated that, similar to previous results for sleep and IL-6, increased WBC counts were related to poor sleep in male shift workers. The findings also agreed with the results of our preliminary study [26].

It is well known that smoking and obesity are related to increased WBC counts [27-29]. In addition to smoking and $\mathrm{BMI}$, the present multiple regression analysis indicated that the WBC count is associated with total AIS score and work pattern as well. Higher WBC counts were encountered particularly in shift workers with sleeping problems. Shift workers with sleeping problems had shorter sleeping hours than those without the problem. However, there was no relation between actual sleeping hours and WBC count (Table 2). This may suggest that, in relation with white blood cells, it is sleep of satisfactory quality rather than the actual sleep duration that is important, which is in accordance with the results of earlier experimental studies showing that increased IL-6 in sleep disturbances was related to quality rather than the duration of sleep [1,2]. Sufficient sleep of a satisfactory quality will be necessary for shift workers in particular.

Sleep disturbance is common in shift work of all kinds [10]. Reduced sleep duration has been associated with increased risks of coronary artery disease [7]. Shift work which includes night shifts is more likely to lead to atherosclerotic disease [11-13]. The present study showed that shift workers with sleeping problems were more likely to have increased WBC counts. The WBC count is thought to be an indicator of inflammatory response, and an increased count is reportedly associated with coronary artery disease and arteriosclerosis [30-33]. Elevated WBC count in shift workers with sleep problems under study may suggest low-grade inflammation that could be linked to cardiovascular disease in shift workers.

The present results have shown that WBC count can be elevated in shift workers with sleeping problems, and that low-grade inflammatory changes might occur more readily in those workers. However, there are several limitations to this study. The present survey was conducted with the fairly low number of subjects, recruited from male workers at a fiber synthetic plant in Japan. Secondly, the WBC count was used as an inflammatory indicator to examine the effect of sleep disturbances. However, the count can be affected by various factors. Further studies will be needed using other inflammatory markers as well.

\section{ACKNOWLEDGEMENTS}

A grant for this study was received from the Aichi Health Promotion Foundation for health promotion projects among its Medical Research and Health Promotion Activities grants.

\section{REFERENCES}

[1] Vgontzas AN, Papanicolaou DA, Bixler EO, et al. Circadian interleukin-6 secretion and quantity and depth of sleep. J Clin Endocrinol Metab 1999; 84: 2603-07.

[2] Hong S, Mills PJ, Loredo JS, Adler KA, Dimsdale JE. The association between interleukin-6, sleep, and demographic characteristics. Brain Behav Immun 2005; 19: 165-72.

[3] Hui L, Hua F, Diandong H, Hong Y. Effects of sleep and sleep deprivation on immunoglobulins and complement in humans. Brain Behav Immun 2007; 21: 308-10.

[4] Born J, Lange T, Hansen K, Mölle M, Fehm HL. Effects of sleep and circadian rhythm on human circulating immune cells. J Immunol 1997; 158: 4454-64.

[5] Dinges DF, Douglas SD, Zaugg L, et al. Leukocytosis and natural killer cell function parallel neurobehavioral fatigue induced by 64 hours of sleep deprivation. J Clin Invest 1994; 93: 1930-9.

[6] Meier-Ewert HK, Ridker PM, Rifai N, et al. Effect of sleep loss on $\mathrm{C}$-reactive protein, an inflammatory marker of cardiovascular risk. JACC 2004; 43: 678-83.

[7] Alvarez GG, Ayas NT. The impact of daily sleep duration on health: a review of literature. Prog Cardiovasc Nurs 2004; 19: 68-9.

[8] Nilsson PM, Rööst M, Engstöm G, Hedblad B, Bereglund G. Incidence of diabetes in middle-aged men is related to sleep disturbance. Diabetes Care 2004; 10: 2464-9.

[9] Knutson KL, Ryden AM, Mander BA, Cauter EV. Role of sleep duration and quality in the risk and severity of type 2 diabetes mellitus. Arch Intern Med 2006; 166: 1768-74.

[10] Akerstedt T. Shift work and disturbed sleep/wakefulness. Occup Med 2003; 53: 89-94.

[11] Karlsson BH, Knutsson AK, Lindahl BO, Alfredsson LS. Metabolic disturbances in male workers with rotating three-shift work. Results of the WOLF study. Int Arch Occup Environ Health 2003; 76: 424-30.

[12] van Amelsvoort LG, Schouten EG, Kok FJ. Impact of one year of shift work on cardiovascular disease risk factors. J Occup Environ Med 2004; 46: 699-706.

[13] Karlsson B, Knutsson A, Lindahl B. Is there an association between shift work and having a metabolic syndrome? Results from a population based study of 27,485 people. Occup Environ Med 2001; 58: 747-52.

[14] Spiegel K, Leproult R, VanCauter E. Impact of sleep debt on metabolic and endocrine function. Lancet 1999; 354: 1435-39.

[15] Ribeiro DCO, Hampton SM, Morgan L, Deacon S, Arendt J. Altered postprandial hormone and metabolic responses in a simulated shift work environment. J Endocrinol 1998; 158: 305-10.

[16] Sookoian S, Gemma C, Fernández Gianotti T, et al. Effects of rotating shift work on biomarkers of metabolic syndrome and inflammation. J Intern Med 2007; 261: 285-92.

[17] Soldatos CR, Dikeos DG, Paparrigopoulos TJ. Athens Insomnia Scale: validation of an instrument based on ICD-10 criteria. J Psychosom Res 2000; 48: 555-60.

[18] Ferentinos P, Kontaxakis V, Havaki-Kontaxaki B, et al. Sleep disturbances in relation to fatigue in major depression. J Psychosom Res 2009; 66: 37-42.

[19] Yen CF, King BH, Chang YP. Factor structure of the Athens Insomnia Scale and its associations with demographic characteristics and depression in adolescents. J Sleep Res 2010; 19: 12-8.

[20] Soldatos CR, Dikeos DG, Paparrigopoulos TJ. The diagnostic validity of the Athens Insomnia Scale. J Psychosom Res 2003; 55: 263-7.

[21] Irwin MR, Wang M, Campomayor CO, Collado-Hidalgo A, Cole S. Sleep deprivation and activation of morning levels of cellular and genomic markers of inflammation. Arch Intern Med 2006; 166: 1756-62.

[22] Vgontzas AN, Zoumakis E, Bixler EO, et al. Adverse effects of modest sleep restriction on sleepiness, performance, and inflammatory cytokines. J Clin Endocrinol Metab 2004; 89: 2119-26.

[23] Mills PJ, von Känel R, Norman D, Natarajan L, Ziegler MG, Dimsdale JE. Inflammation and sleep in healthy individuals. Sleep 2007; 30: 729-35.

[24] Frey DJ, Fleshner M, Wright KP Jr. The effects of 40 hours of total sleep deprivation on inflammatory markers in healthy young adults. Brain Behav Immun 2007; 21: 1050-7.

[25] Liukkonen T, Räsänen $\mathrm{P}$, Ruokonen A, et al. C-reactive protein levels and sleep disturbances: observations based on the Northern 
Finland 1966 Birth Cohort study. Psychosom Med 2007; 69: 75661.

[26] Nishitani N, Sakakibara H. Subjective poor sleep and white blood cell count in male Japanese workers. Ind Health 2007; 45: 296-300.

[27] Hasegawa T, Negishi T, Deguchi M. WBC count, atherosclerosis and coronary risk factors. J Atheroscler Thromb 2002; 9: 219-23.

[28] Nakanishi N, Suzuki K, Tatara K. Association between lifestyle and white blood cell count: a study of Japanese male office workers. Occup Med 2003; 53: 135-7.

[29] Saito I, Yonemasu K, Inami F. Association of body mass index, body fat, and weight gain with inflammation markers among rural residents in Japan. Circ J 2003; 67: 323-9.

[30] Albert MA, Ridker PM. Inflammatory biomarkers in African Americans: a potential link to accelerated atherosclerosis. Cardiol Med 2004; 5: 522-7.
[31] Ensrud K, Grimm RH. The white blood cell count and risk for coronary heart disease. Am Heart J 1992; 124: 207-13.

[32] Ichihara Y, Ohno J, Suzuki M, Anno T, Sugino M, Nagata K. Higher C-reactive protein concentration and white blood cell count in subjects with more coronary risk factors and/or lower physical fitness among apparently healthy Japanese. Circ J 2002; 66: 67784.

[33] Orakzai SH, Orakzai RH, Nasir K, Carvalho JA, Blumenthal RS, Santos RD. Relationship between white blood cell count and Framingham Risk Score in asymptomatis men. Arch Med Res 2007; 38: 386-91.

(C) Nishitani and Sakakibara; Licensee Bentham Open.

This is an open access article licensed under the terms of the Creative Commons Attribution Non-Commercial License (http://creativecommons.org/licenses/by-nc/3.0/) which permits unrestricted, non-commercial use, distribution and reproduction in any medium, provided the work is properly cited. 